\title{
Cesium-adsorption mechanisms of woody charcoal discussed on the basis of its functional groups and nanostructure
}

\author{
Takayuki Yamagishi ${ }^{1}$, Kaoru Nishikiori ${ }^{2}$, Yasuji Kurimoto ${ }^{3}$ and Shigeru Yamauchi ${ }^{3 *}$
}

\begin{abstract}
The present study examined the $\mathrm{Cs}^{+}$-adsorption behavior of Japanese oak (Quercus serrata Thunb.) charcoal (OC) samples carbonized at 300,500 , and $700^{\circ} \mathrm{C}$ to clarify the adsorption mechanisms from aqueous solution. Adsorption isotherms indicated that the $\mathrm{Cs}^{+}$-adsorption ability of $\mathrm{OC}$ depended strongly on carbonization temperature (CT) and suggested that the ability reached a maximum within the $\mathrm{CT}$ range from 300 to $700^{\circ} \mathrm{C}$. Infrared-photoacoustic (IR$\mathrm{PA}$ ) and Raman spectra of OC samples were obtained to investigate the functional groups and nanostructure in OC. Raman signals exhibited graphite precursor production even in OC synthesized at $300^{\circ} \mathrm{C}$. IR-PA spectral bands provided positive evidence that $\mathrm{OC}$ carbonized at 300 or $500^{\circ} \mathrm{C}$ contained sufficient $\mathrm{OH}$ groups, and some of which were free from hydrogen bonding. Detecting free $\mathrm{OH}$ groups was the most important outcome in this study as it allowed exploration of the $\mathrm{OC}$ nanostructure. The experimental data indicated that the primary attraction to $\mathrm{Cs}^{+}$is due to the surface $\mathrm{OH}$ groups in $\mathrm{OC}$, therefore offering an approach to synthesizing woody charcoal with a high $\mathrm{Cs}^{+}$-adsorption performance.
\end{abstract}

Keywords: Cesium, Charcoal, Adsorption, Nanostructure, Hydroxy group, Hydrogen bond, Surface complex

\section{Introduction}

The nuclear power plant accident caused by the Great East Japan Earthquake (2011) has raised several important and serious issues and led to many countries considering shutting down of their nuclear power plants. It is, however, unlikely that all power plant systems on Earth employing uranium nuclear fission will be brought to a standstill in the near future. Thus, it is essential to take rapid and appropriate measures to prevent nuclear pollutants from spreading, although the effective safeguard against the leakage of radioactive substances from nuclear power reactors is the top priority. Cs-134 and Cs-137 are the most troublesome radioisotopes with respect to decontamination and have been the most difficult to remove from contaminated areas in Fukushima Prefecture. This situation would recur as a result of future

\footnotetext{
${ }^{*}$ Correspondence: sigeru@iwt.akita-pu.ac.jp

${ }^{3}$ Institute of Wood Technology, Akita Prefectural University, 11-1

Kaieisaka, Noshiro 016-0876, Japan

Full list of author information is available at the end of the article
}

nuclear power plant accident; hence, high-performance and economical adsorptive materials for $\mathrm{Cs}^{+}$are urgently required.

Many researchers have studied $\mathrm{Cs}^{+}$adsorption by inorganic substances, such as synthesized zeolites and Prussian-blue-type complexes. In contrast, only a few studies have reported char made from plant biomass as a $\mathrm{Cs}^{+}$ adsorptive [1-4] other than ours [5-10] despite 8 years passing from the Fukushima accident, because the $\mathrm{Cs}^{+}$-adsorption ability of ordinary biochar is inferior to that of inorganic adsorptives. However, woody charcoal is inexpensive and can be mass-produced easily, and its remarkable advantage is considerable volume reduction by combustion.

We have previously investigated the $\mathrm{Cs}^{+}$-adsorption behavior of commercial charcoals used in Japan from aqueous solutions. These studies suggested that the content of acidic functional groups, such as hydroxy $(\mathrm{OH})$ or carboxy groups, included in the charcoal is a governing factor determining the ability to adsorb $\mathrm{Cs}^{+}$ from aqueous solution [10]. The functional groups and 
nanostructures in woody charcoal were partially elucidated [11, 12], but the structure has not been completely determined because of their complicated nature.

Our objective is to examine the mechanisms involved in $\mathrm{Cs}^{+}$adsorption from aqueous solution onto charcoal surfaces in terms of surface functional groups and nanostructure in more detail. In this paper, Japanese oak (Quercus serrata Thunb.) charcoal (OC) samples were characterized using infrared-photoacoustic (IR-PA) and Raman spectroscopy.

Infrared (IR) spectroscopy is a helpful tool for identifying functional groups in wood. Although ordinary IR techniques do not always provide a fine spectrum for black or dark samples such as charcoal and degraded wood due to non-resonant absorption, IR-PA technique is suitable for obtaining the IR spectra of such samples. For example, this technique was used to such samples, revealing that it is a useful method for determining chemical changes in functional groups [12-14]. It is well known that Raman signals provide information about $\mathrm{sp}^{2}$ bonding in carbon materials. We discuss the nature of the chemical attraction between $\mathrm{Cs}^{+}$and charcoal surfaces based on the spectroscopic characterization.

\section{Experimental}

\section{Chemicals}

Special-grade cesium chloride anhydride and microcrystalline cellulose powder were obtained commercially from FUJIFILM Wako Pure Chemical Co.

\section{Carbonization of Japanese oak wood and cellulose}

Japanese oak trees growing wild in Akita Prefecture in Japan were cut down, and their stems were cut into round slices with a thickness of $5 \mathrm{~cm}$. The slices were dried indoors at ambient temperature for over 3 months. After removing bark and heartwood, the sapwood blocks were ground into powder using a cutting mill. The Japanese oak sapwood and cellulose powders were carbonized under a $\mathrm{N}_{2}$ flow $(150 \mathrm{~mL} / \mathrm{min})$ in a quartz tube kiln (Isuzu Seisakusho Ltd., Japan). The furnace temperature was programmed to increase from room temperature to $105^{\circ} \mathrm{C}$ at $10{ }^{\circ} \mathrm{C} / \mathrm{min}$, remain at $105^{\circ} \mathrm{C}$ for $1 \mathrm{~h}$, to subsequently increase to 300,500 , or $700^{\circ} \mathrm{C}$ at $10^{\circ} \mathrm{C} / \mathrm{min}$, and finally remain at the desired temperatures (carbonization temperature, CT) to yield charcoal. Japanese oak charcoal (OC) samples synthesized at 300,500 , and $700{ }^{\circ} \mathrm{C}$ are denoted OC300, OC500, and OC700, respectively. In the same way, cellulose charcoal (CC) samples synthesized at 300,500 , and $700{ }^{\circ} \mathrm{C}$ are similarly denoted CC300, CC500, and CC700, respectively. Moreover, the holding time (HT) at the CT is appended to the sample name; for example, $\mathrm{OC}$ carbonized at $500{ }^{\circ} \mathrm{C}$ for $2.0 \mathrm{~h}$ is referred to as OC500-2. OC powder (40-80 mesh) was used as an adsorbent for $\mathrm{Cs}^{+}$. The $\mathrm{OC}$ and $\mathrm{CC}$ samples were stored in a capped glass tube in air.

\section{Aqueous $\mathrm{CsCl}$ solution}

After drying at $100{ }^{\circ} \mathrm{C}$ for 1 day, $\mathrm{CsCl}$ powder was weighed and dissolved in water. The solution was prepared using water deionized through a column packed with ion-exchange resins. The initial concentration was $2.50 \times 10^{-5} \mathrm{~mol} / \mathrm{L}\left(\mathrm{Cs}^{+} 3.32 \mathrm{mg} / \mathrm{L}\right)$.

\section{Raman spectra of OC and CC}

Raman spectra were obtained using a Raman spectrometer (inVia Raman Microscope, Renishaw PLC, UK) with 532-nm laser excitation (1.5-15 mW). Back-scattered Raman signals were collected through a microscope $(100 \times$ objective lens) with a spectral resolution of approximately $3 \mathrm{~cm}^{-1}$, and the exposure time was $50 \mathrm{~s}$. The sample powder was thinly and evenly spread on a glass plate. Wavenumber calibration was carried out using the $520 \mathrm{~cm}^{-1}$ line for a silicon wafer and the $1332 \mathrm{~cm}^{-1}$ line for diamond.

\section{IR-PA spectra of $O C$ and $C C$}

IR-PA spectra were recorded using a JIR7000W spectrometer (JEOL Ltd., Japan) coupled with an IR-PA spectroscopy module (IR-PAS 1000). The spectra were obtained from 300 accumulations with a spectral resolution of ca. $4 \mathrm{~cm}^{-1}$. A thin cell made of $\mathrm{Al}$ (diameter $5 \mathrm{~mm}$ ) was filled with the sample powder. OC and CC samples were exposed to air for several days and measured without drying. Photoacoustic signals were collected upon purging a cell bench with He gas. The moving-mirror velocity was set to $1.6 \mathrm{~mm} / \mathrm{s}$ for all measurements. Carbon black was used as a reference. Wavenumber calibration was carried out based on the 1028, 1601, and $3060 \mathrm{~cm}^{-1}$ lines for polystyrene. The original band intensities were not altered mathematically, although baseline corrections were conducted as required.

\section{$\mathrm{Cs}^{+}$adsorption from aqueous $\mathrm{CsCl}$ solution to $\mathrm{OC}$ powder} The OC samples were dried at $105{ }^{\circ} \mathrm{C}$ for $3 \mathrm{~h}$ before mass measurements. Aqueous $\mathrm{CsCl}$ solution $(50 \mathrm{~mL})$ containing $\mathrm{OC}$ adsorbent $(0.10,0.20,0.40,0.80$, or $1.60 \mathrm{~g})$ in a capped Erlenmeyer flask was shaken using an orbital shaker at $23 \pm 2{ }^{\circ} \mathrm{C}$ for $24 \mathrm{~h}$ and then removed by filtration through a nylon-membrane microfilter (Millex-HN filters, SLHN033NS, Millipore Ireland, Ltd., Ireland). The $\mathrm{pH}$ of the filtrate was measured with a $\mathrm{pH}$ meter. The $\mathrm{Cs}^{+}$concentration in the filtrate was determined using an inductively coupled plasma mass spectrometry (ICP-MS) (Agilent 7700x, Agilent Technologies, Ltd., US) with an internal standard method (standard isotope ${ }^{115} \mathrm{In}$ ). The ICP-MS measurements 
were repeated three times for each sample solution. Relative standard deviations were all within $3.0 \%$. The process of calculating the $\mathrm{Cs}^{+}$concentration on the charcoal was described previously $[6-8,10]$.

\section{Results and discussion}

Mass reduction of $O C$ by carbonization

Table 1 summarizes the mass reduction rates for the OC samples. The OC300 required over $1.0 \mathrm{~h}$ of HT until its weight was constant. The mass reduction of OC500 was likely to be nearly completed within $1.0 \mathrm{~h}$, and the mass of OC700 became essentially constant before $0.5 \mathrm{~h}$. Thus, the changes in mass reduction given in Table 1 suggest that the pyrolysis of Japanese oak sapwood progressed adequately within $2.0 \mathrm{~h}$ of HT in the carbonizing device, even at a $\mathrm{CT}$ of $300{ }^{\circ} \mathrm{C}$.

\section{$\mathrm{Cs}^{+}$-adsorption isotherms from aqueous solution onto $\mathrm{OC}$} Figure 1 depicts the adsorption isotherms of OC3002 , OC500-2, and OC700-2. The isotherms indicate that the $\mathrm{Cs}^{+}$-adsorption ability of $\mathrm{OC}$ follows the order: OC700- $2<$ OC300- $2<$ OC500-2. Therefore, it is likely that the adsorption ability increases with $\mathrm{CT}$ from $300{ }^{\circ} \mathrm{C}$ up to a certain optimum temperature and then decreases to at least $700{ }^{\circ} \mathrm{C}$. The change in $\mathrm{Cs}^{+}$-adsorption ability with $\mathrm{CT}$ can be expected to provide insights into the functional groups and nanostructures of $\mathrm{OC}$, although the optimum temperature may fluctuate with carbonization conditions. The results shown in Fig. 1 are not incompatible with the previous

Table 1 OC mass reduction rate

\begin{tabular}{llll}
\hline $\mathbf{C T}\left({ }^{\circ} \mathbf{C}\right)$ & HT of $\mathbf{C T}(\mathbf{h})$ & OC sample & MR rate (\%) \\
\hline 300 & 0.5 & OC300-0.5 & 40.3 \\
& 1.0 & OC300-1 & 44.8 \\
& 2.0 & OC300-2 & 48.4 \\
& 3.0 & OC300-3 & 48.5 \\
500 & 0.5 & OC500-0.5 & 72.8 \\
& 1.0 & OC500-1 & 73.3 \\
& 2.0 & OC500-2 & 73.5 \\
700 & 3.0 & OC500-3 & 73.6 \\
& 0.5 & OC700-0.5 & 76.1 \\
& 1.0 & OC700-1 & 76.1 \\
& 2.0 & OC700-2 & 76.2 \\
& 3.0 & OC700-3 & 76.5
\end{tabular}

OC: Japanese oak charcoal; CT: carbonization temperature; HT: holding time; MR: mass reduction

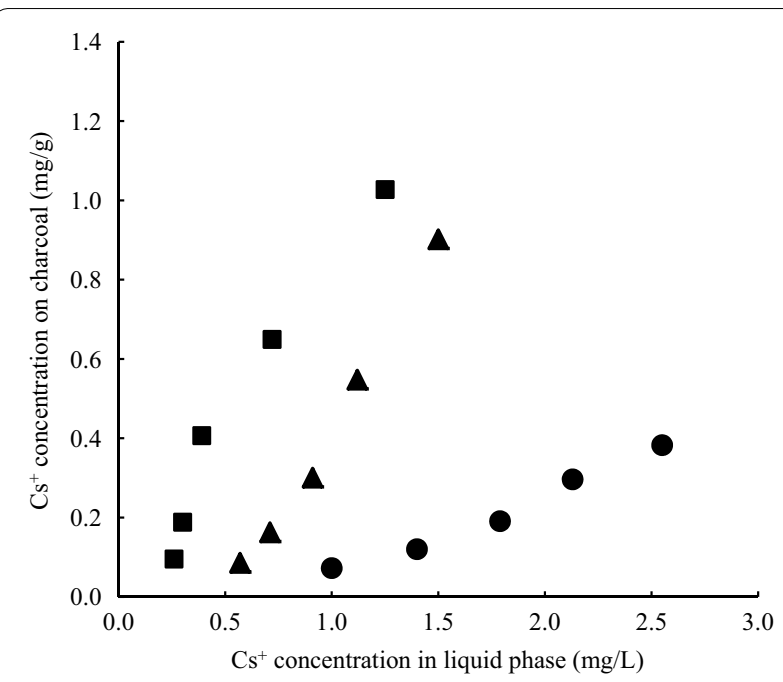

Fig. 1 Isotherms of $\mathrm{Cs}^{+}$-adsorption from aqueous $\mathrm{CsCl}$ solution onto OC300-2 (filled triangles), OC500-2 (filled squares), and OC700-2 (filled circles)

work on the $\mathrm{Cs}^{+}$-adsorption ability of commercial charcoals [10].

\section{Raman spectra of OC and CC}

Figure 2 shows Raman spectra of OC and CC from 1800 to $1000 \mathrm{~cm}^{-1}$. OC and CC samples carbonized at the same CT showed no remarkable changes in the Raman spectral shape with increasing HT when HT was longer than $1.0 \mathrm{~h}$.

All the OC samples exhibit clear broad D and G bands, characteristic of graphite-like structures. The peak position of $\mathrm{G}$ band is nearly independent of CT, whereas that of $\mathrm{D}$ band clearly shifts to lower wavenumber with the increase in CT. The widths of the $\mathrm{D}$ and $\mathrm{G}$ bands for OC700-2 appear narrower than those for OC300-2 and OC500-2. These spectral changes are in good agreement with Raman data for Japanese cedar charcoal reported previously $[15,16]$.

The D- and G-band shapes for CC500-2 and CC700-2 are very similar to those for OC500-2 and OC7002 , respectively. The Raman scattering intensity for CC300-2 is extremely weak, and the D band is not easily detectable, although the $\mathrm{G}$ band appears similar to that for OC300-2. The Raman spectral differences between OC300-2 and CC300-2 suggest that an uncarbonized portion of CC300-2 was large compared with that of OC300-2. In other words, it seems likely that all of carbonization reactions of hemicellulose and/or lignin were almost completed even below $300{ }^{\circ} \mathrm{C}[17$, 18]. The narrowing of the $D$ and $G$ bands suggests that the stereoregularity of graphite precursors produced by carbonization is enhanced with increasing CT. 


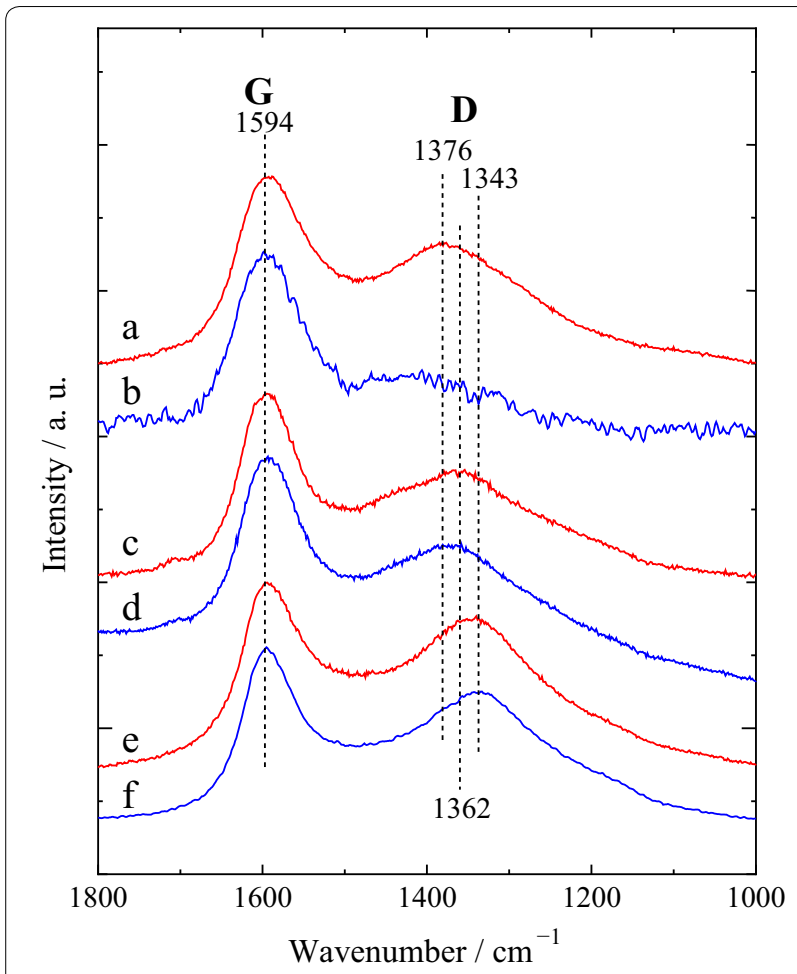

Fig. 2 Raman spectra in the $1800-1000 \mathrm{~cm}^{-1}$ region for a OC300-2 (red solid line), b CC300-2 (blue solid line), c OC500-2 (red solid line), d CC500-2 (blue solid line), e OC700-2 (red solid line), and f CC700-2 (blue solid line)

\section{IR-PA spectra of OC and CC}

The IR-PA spectra also showed no remarkable changes in shape with increasing HT when HT was above $1.0 \mathrm{~h}$. Figure 3 shows IR-PA spectra in the $4000-2500 \mathrm{~cm}^{-1}$ range for OC300-2, OC500-2, OC700-2, and raw Japanese oak sapwood.

As shown in Fig. 3a, a band assigned to $\mathrm{C}-\mathrm{H}$ stretching vibrational modes of $\mathrm{CH}_{3}-,-\mathrm{CH}_{2}-$, and $>\mathrm{CH}-$ groups appears around $2900 \mathrm{~cm}^{-1}$. It was difficult to quantitatively evaluate the band intensities in the IR-PA spectra because of no appropriate internal standard band. However, it can be reasonably assumed that the band around $2900 \mathrm{~cm}^{-1}$ becomes weaker as CT increases and disappears at $700{ }^{\circ} \mathrm{C}$, since all the spectra shown in Fig. 3 are displayed at the same vertical scale and their band intensities are not altered mathematically. Furthermore, a new band at about $3050 \mathrm{~cm}^{-1}$ appears at $500{ }^{\circ} \mathrm{C}$, which is attributed to $\mathrm{sp}^{2} \mathrm{C}-\mathrm{H}$ stretching vibrations $[13,19]$.

A strong and extremely broad peak assigned to $\mathrm{O}-\mathrm{H}$ stretching vibrations appears between 3700 and $3100 \mathrm{~cm}^{-1}$ in the raw wood spectrum, and this broadening is caused by hydrogen bonding. This band also diminishes with increasing $\mathrm{CT}$ and is undetectable at $700{ }^{\circ} \mathrm{C}$. Additionally, it seems that the peak top of this band shifts

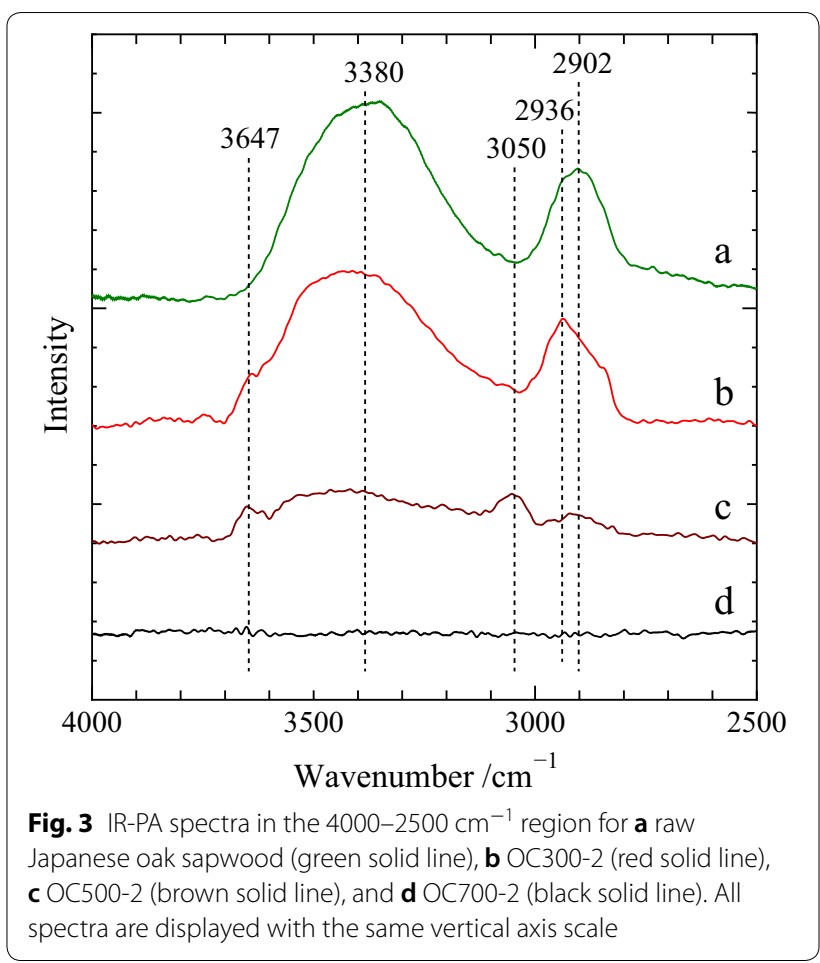

to higher wavenumber with the increase in CT. In general, the stronger the hydrogen bonding is, the lower the wavenumber of the $\mathrm{O}-\mathrm{H}$ stretching vibrational mode becomes. Therefore, this shift suggests that the effects of hydrogen bonding on $\mathrm{OH}$ groups are comprehensively weakened with increasing CT.

It is interesting to note that a band at about $3650 \mathrm{~cm}^{-1}$ is clearly detected in the $\mathrm{O}-\mathrm{H}$ stretching vibration region (Fig. 3b, c). The band appears as a shoulder in the OC300-2 spectrum and a well-resolved peak in the OC500-2 spectrum. It is attributed to $\mathrm{O}-\mathrm{H}$ stretching vibrations of alcoholic and/or phenolic $\mathrm{OH}$ groups free from hydrogen bonding [20]. Few reports are available on detecting free $\mathrm{OH}$ groups in the solid state by IR or Raman spectroscopy without deconvolution processing. The direct detection of free $\mathrm{OH}$ groups is the most important outcome in this study and provides useful information on the $\mathrm{OC}$ nanostructures.

Figure 4 illustrates a simplified model of the nanostructures in OC300 and OC500. As shown in Fig. 4a, raw Japanese oak wood contains numerous $\mathrm{OH}$ groups. Almost all the $\mathrm{OH}$ groups form hydrogen bonds with neighboring functional groups having $\mathrm{O}$ atoms or water molecules. Water evaporation and pyrolysis of wood constituents occur with heating. Hence, pyrolysis leads to a decrease in the amount of $\mathrm{OH}$ groups and causes nonuniform contraction of wood cell walls. Consequently, many pores with free $\mathrm{OH}$ groups on their surfaces are 


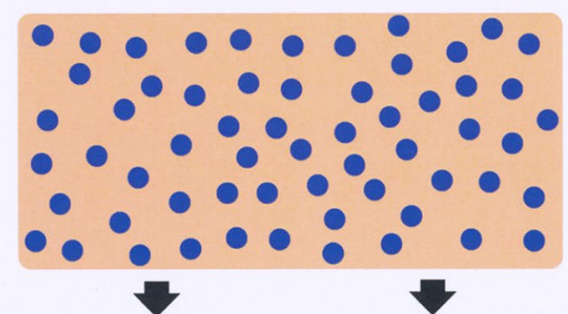

b
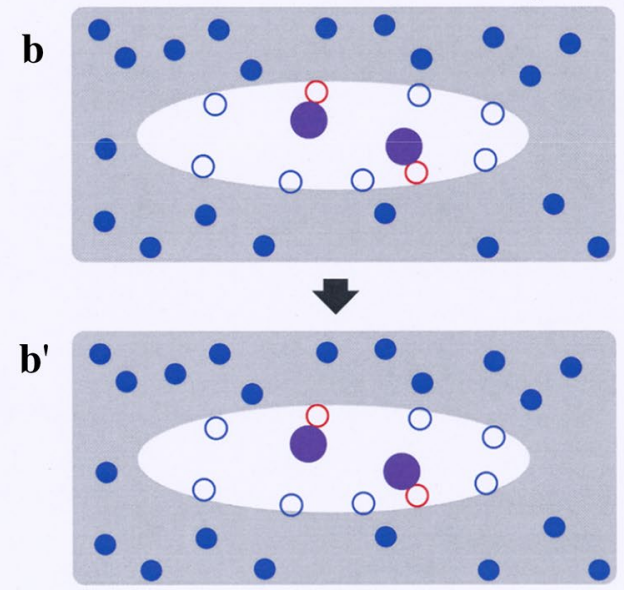

c
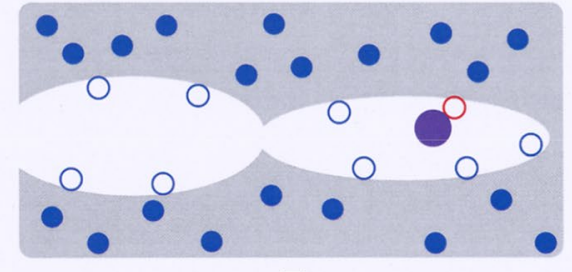

C

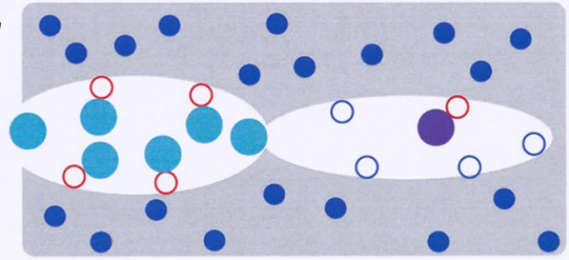

Fig. 4 Schematic of changes in OC300 or OC500 nanostructures. a raw Japanese oak wood, b, c freshly synthesized OC 300 or OC500, and $\mathbf{b}$ ' and c' OC300 or OC500 kept in air for a long period after synthesis. Small blue filled circles: OH groups in bulk of solid, small blue open circles: free OH groups on surface, small red open circles: hydrogen-bonded $\mathrm{OH}$ groups on surface, large light-blue filled circles: water molecules moved from outside, and large purple filled circles: water molecules produced by pyrolysis of wood constituents

formed in OC300-2 and OC500-2, as illustrated in Fig. $4 \mathrm{~b}$ and/or c. The pores may be more appropriately called crevices or crevasses on the molecular level, since no activation treatments were applied to any of the $\mathrm{OC}$ samples. It is known that water is generated by pyrolysis of wood components $[18,21]$. The water molecules may be trapped in the pores and form hydrogen bonds with surface $\mathrm{OH}$ groups. If external water molecules can move into a pore, $\mathrm{OH}$ groups will form hydrogen bonds with them, as shown in the left side of Fig. 4c'. Otherwise, the $\mathrm{OH}$ groups will remain free from hydrogen bonds, as shown in Fig. 4b' and the right side of Fig. 4c', even when the OC samples are kept in air for a long time.

Figure 5 depicts the $2000-800 \mathrm{~cm}^{-1}$ region of the IR-PA spectra shown in Fig. 3. As shown in the bottom spectrum, OC700-2 also exhibits no IR bands in this region, suggesting that organic functional groups derived from raw wood are completely thermally decomposed up to $700{ }^{\circ} \mathrm{C}$ as with Japanese cedar charcoal [13].

The spectral changes with $\mathrm{CT}$ in the range of $1800-$ $1550 \mathrm{~cm}^{-1}$ are remarkably interesting and contain potential information about the $\mathrm{OC}$ nanostructures. The IR bands appearing at 1740 and $1652 \mathrm{~cm}^{-1}$ in the IR spectrum of raw wood (Fig. $5 \mathrm{a}$ ) are assigned to $\mathrm{C}=\mathrm{O}$

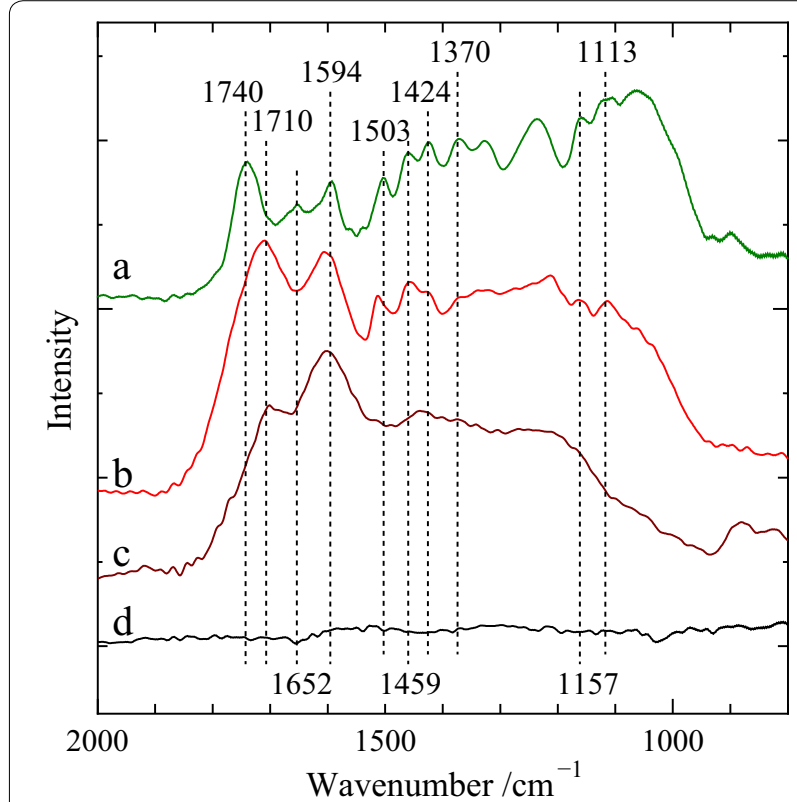

Fig. 5 IR-PA spectra in the $2000-800 \mathrm{~cm}^{-1}$ region for a raw Japanese oak sapwood (green solid line), b OC300-2 (red solid line), c OC500-2 (brown solid line), and $\mathbf{d}$ OC700-2 (black solid line). All spectra are displayed with the same vertical axis scale 
in carboxy group, and ethylenic $\mathrm{C}=\mathrm{C}$ in coniferyl alcohol and/or $\mathrm{C}=\mathrm{O}$ in coniferyl aldehyde, respectively [22]. The band at $1594 \mathrm{~cm}^{-1}$ is attributed to aromatic six-membered rings.

As seen in Fig. 5b, OC300-2 exhibits no peaks at 1740 and $1652 \mathrm{~cm}^{-1}$; however, a broad new band appears at $1710 \mathrm{~cm}^{-1}$. A band near $1594 \mathrm{~cm}^{-1}$ is also observed, but this is broader than that in Fig. 5a. The resolution among IR bands in the OC300-2 spectrum is poor, although bands at about 1459, 1424, 1370, and $1157 \mathrm{~cm}^{-1}$ are observable as peaks or shoulders. Peaks at about 1710 and $1594 \mathrm{~cm}^{-1}$ are clearly detected in the OC500-2 spectrum (Fig. 5c), but other bands in the $1500-1100 \mathrm{~cm}^{-1}$ region are indistinguishable from one another despite their strong intensities. The bands at 1710 and $1594 \mathrm{~cm}^{-1}$ (Fig. 5b, c) indicate that OC300-2 and $\mathrm{OC} 500-2$ contain $\mathrm{C}=\mathrm{O}$ groups and aromatic sixmembered rings [12]. It is, however, anticipated from the relative intensity and width of the bands that the $\mathrm{C}=\mathrm{O}$ groups and aromatic rings were not derived from the raw wood, but were formed during the carbonization process.

Figure 6 shows IR-PA spectra of OC and CC samples from 4000 to $800 \mathrm{~cm}^{-1}$. As cellulose is a major constituent of wood, the overall spectral shape for cellulose (Fig. 6b) is similar to that of Japanese oak wood (Fig. 6a). However, the spectral shape between 1800 and $1550 \mathrm{~cm}^{-1}$ is quite different from that of Japanese oak wood because of the absence of $\mathrm{C}=\mathrm{O}$ and phenyl groups. In contrast, as shown in Fig. 6d, f, CC300-2 and CC500-2 exhibit strong broad bands at about 1710 and $1594 \mathrm{~cm}^{-1}$, similar to those for OC300-2 and OC5002. As was referred to Fig. 5, the IR-PA spectra of CC provide strong evidence that the two bands are not due to residual functional groups derived from raw wood, but are instead mainly due to functional groups formed by heat treatment. The bands at 1710 and $1594 \mathrm{~cm}^{-1}$ observed for OC300-2, CC 300-2, OC500-2, and $\mathrm{CC} 500-2$ are attributed to $\mathrm{C}=\mathrm{O}$ groups and aromatic rings, respectively, and the latter band suggests that precursors of graphite were formed in the charcoal samples. This is supported by the appearance of a band at $3050 \mathrm{~cm}^{-1}$ due to $\mathrm{C}-\mathrm{H}$ bonds of $\mathrm{sp}^{2} \mathrm{C}$ in the CC500-2 spectrum, as is similar to OC500-2 spectrum shown in Fig. 3.

These IR-PA results are consistent with the Raman spectra shown in Fig. 2. Moreover, the shape of the broad band $\left(3700-3100 \mathrm{~cm}^{-1}\right)$ for the CC samples is very similar to that of the corresponding OC samples; CC300-2 and CC500-2 also exhibit a shoulder and a peak at about $3650 \mathrm{~cm}^{-1}$, respectively. Hence, it can be assumed that similar nanostructural changes illustrated in Fig. 4 occurred in the CC samples.

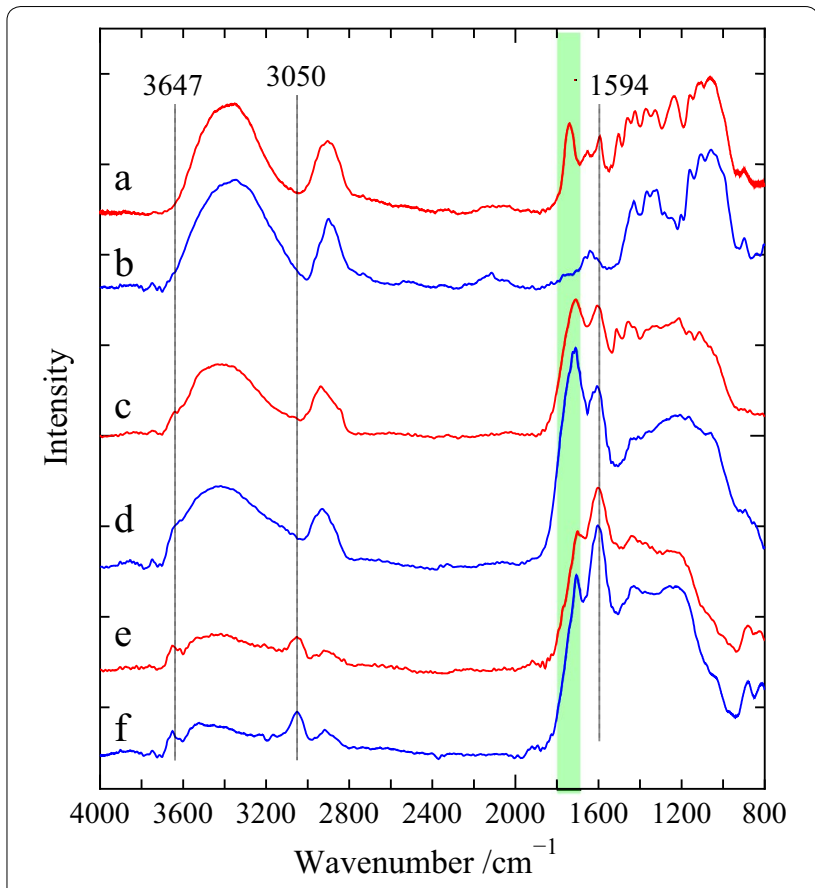

Fig. 6 IR-PA spectra in the $4000-800 \mathrm{~cm}^{-1}$ region for a raw Japanese oak sapwood, b cellulose powder, c OC300-2, d CC300-2, e OC500-2, and $\mathbf{f}$ CC500-2. Light green belt: wavenumber region from 1800 to $1700 \mathrm{~cm}^{-1}$. All spectra are displayed with the same vertical axis scale

\section{Mechanisms for $\mathrm{Cs}^{+}$adsorption onto $\mathrm{OC}$ from aqueous solution}

We describe here comprehensive mechanisms for $\mathrm{Cs}^{+}$ adsorption onto OC samples. The IR-PA spectra of OC samples showed that the functional groups derived from raw Japanese oak wood decreased with increasing $\mathrm{CT}$ and were thoroughly decomposed up to $700{ }^{\circ} \mathrm{C}$. Furthermore, the spectra indicated that almost all the carboxy groups were decomposed up to $300{ }^{\circ} \mathrm{C}$. In contrast, it was evident from the IR-PA spectra of OC500-2 that a considerable portion of the $\mathrm{OH}$ groups remained even at $500{ }^{\circ} \mathrm{C}$, although their amount decreased with the increase in CT. Thus, it can be assumed that the $\mathrm{OH}$ groups are the primary acidic functional groups in OC300 and OC500.

It has been expected that acidic functional groups would play an important role in the capture of $\mathrm{Cs}^{+}$by commercial woody charcoals $[9,10]$. By releasing a proton $\left(\mathrm{H}^{+}\right)$, acidic functional groups can obtain a negative charge in aqueous solution. Since $\mathrm{Cs}^{+}$is a cation, it is electrostatically attracted to negatively charged functional groups.

Based on the investigation into IR-PA spectra of OC, we reach the conclusion that almost all the acidic functional groups in OC300 and OC500 are OH groups. As described above, the $\mathrm{Cs}^{+}$-adsorption ability followed 


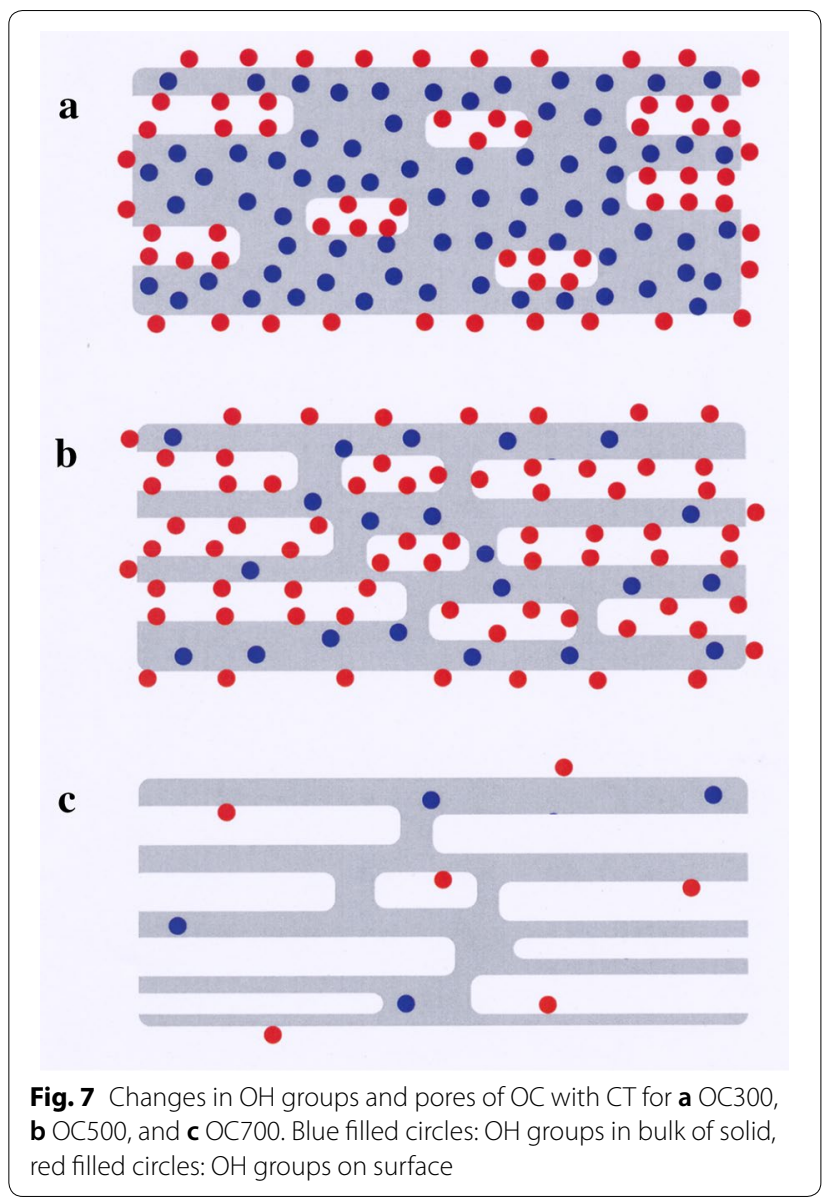

the order $\mathrm{OC} 700<\mathrm{OC} 300<\mathrm{OC} 500$, inferring that the ability reaches a maximum at a certain $\mathrm{CT}, \mathrm{CT}_{\mathrm{M}}$, $\left(300{ }^{\circ} \mathrm{C}<\mathrm{CT}_{\mathrm{M}}<700{ }^{\circ} \mathrm{C}\right)$ and then decreases with a further increase in CT. Accordingly, the dependence of the $\mathrm{Cs}^{+}$-adsorption ability on CT cannot be explained only by changes in the total amount of $\mathrm{OH}$ groups per unit weight in OC samples. On the other hand, it is inferred from other studies [23-25] that the specific area of charcoal determined by $\mathrm{N}_{2}$-adsorption increases monotonously with increasing CT up to $600{ }^{\circ} \mathrm{C}$ when no activation processes are applied to the charcoal.

Consequently, the nanostructure and acidic functional groups presumably change as illustrated in Fig. 7. The specific area of OC300 is still small (i.e., OC300 contains few pores), although most of the $\mathrm{OH}$ groups remain, and thus, the percentage of the $\mathrm{OH}$ groups able to directly make contact with $\mathrm{Cs}^{+}$(the surface $\mathrm{OH}$ groups) is considerably low (Fig. 7a). The total number of $\mathrm{OH}$ groups in OC500 is lower than that in OC300 owing to the pyrolysis progression. However, the number of surface $\mathrm{OH}$ groups is higher because of an increase in surface area (Fig. 7b). The $\mathrm{Cs}^{+}$-adsorption ability of OC700 decreases evidently, because almost all the $\mathrm{OH}$ groups are broken down thermally.

This explanation raises the issue of why the $\mathrm{Cs}^{+}$-adsorption ability of OC700 was not negligible despite no $\mathrm{O}-\mathrm{H}$ stretching vibrations being detected by IR-PA spectroscopy. This indicates that $\mathrm{Cs}^{+}$adsorption to OC700 is due to factors other than $\mathrm{OH}$ groups.

The Raman and IR-PA spectra suggest that the graphite precursors having $\pi$-electrons are sufficiently contained in OC700. However, it is very difficult for hydrated $\mathrm{Cs}^{+}$ to be intercalated between the stacks in terms of the space of graphite layers [26] and the diameter of hydrated $\mathrm{Cs}^{+}[27,28]$, if the stacks of graphitic carbon in OC700 grow considerably. Meanwhile, it is known that the cation $-\pi$ interaction occurs in simple aromatics [29]. Therefore, the surface $\pi$-electrons in OC700 are likely to be able to capture $\mathrm{Cs}^{+}$, because the interactions are comparable to typical hydrogen bonds [30, 31]. Accordingly, it is assumed that the $\mathrm{Cs}^{+}$-adsorption ability in $\mathrm{OC700}$ is caused largely by the interaction between $\mathrm{Cs}^{+}$and the surface $\pi$-electrons, although the contribution from the $\pi$-electrons to $\mathrm{Cs}^{+}$-adsorption performance is likely to be much smaller than that from an $\mathrm{OH}$ group. Moreover, this interaction may explain why the $\mathrm{Cs}^{+}$-adsorption ability of commercial charcoal carbonized above $1000{ }^{\circ} \mathrm{C}$ is not negligibly low despite no $\mathrm{OH}$ groups [10].

In conclusion, the $\mathrm{Cs}^{+}$-adsorption ability of charcoal depends mainly on the number of surface $\mathrm{OH}$ groups per unit weight of charcoal. The present study demonstrates that a new carbonization technique that preserves $\mathrm{OH}$ groups as far as possible and maximally extends the surface area is essential for producing high-performance charcoal for $\mathrm{Cs}^{+}$adsorption.

Since surface $\mathrm{OH}$ groups play the most important role in capturing $\mathrm{Cs}^{+}$, an investigation into chemical species formed from $\mathrm{Cs}^{+}$and surface $\mathrm{OH}$ groups is required to achieve a deeper understanding of the $\mathrm{Cs}^{+}$-adsorption mechanism in charcoal. Figure 8 illustrates presumable models of the interactions between $\mathrm{Cs}^{+}$and surface $\mathrm{OH}$ groups (i.e., surface complexes). In general, ions interacting with a solid surface are classified into two types [32, 33]. The first involves ions binding directly to the surface without intervening solvent molecules. Chemical species containing such ions are referred to as inner-sphere complexes (Fig. 8a-c). The second involves ions that indirectly interact with the surface via solvated molecules (e.g., water, methanol, or ethanol); complexes containing such ions are known as outer-sphere complexes (Fig. 8d, e). This concept was recently applied to $\mathrm{Cs}^{+}$adsorption by soils [34].

Among these surface complexes, we focus on an inner-sphere complex illustrated in Fig. 8c and an outer-sphere complex shown in Fig. 8e. In the former 


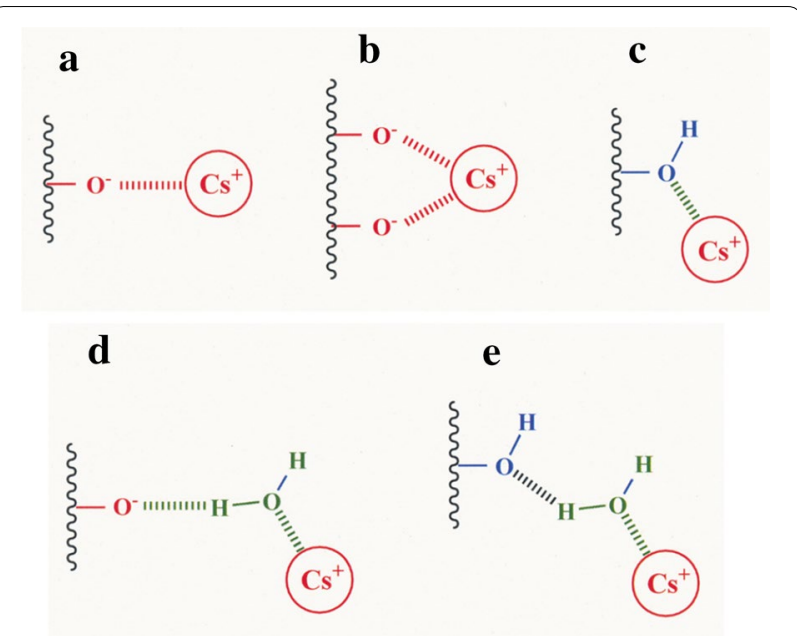

Fig. 8 Structures of surface $\mathrm{Cs}^{+}$complexes for $\mathbf{a}-\mathbf{c}$ inner-sphere complexes, $\mathbf{d}$, e outer-sphere complexes. Black wavy line: surface of charcoal, red hashed line: ionic bond, green hashed line: coordinate or hydrogen bond, green $\mathrm{H}_{2} \mathrm{O}$ : coordinated water molecule, blue $\mathrm{OH}$ : non-ionized $\mathrm{OH}$ group on surface, red $\mathrm{O}^{-}$: ionized $\mathrm{OH}$ group on surface

complex, $\mathrm{Cs}^{+}$is coordinated by a neutral $\mathrm{OH}$ through a surface $\mathrm{O}$ atom. The latter complex has a water molecule coordinating to $\mathrm{Cs}^{+}$, which forms a hydrogen bond with a neutral $\mathrm{OH}$. Thus, electrically neutral $\mathrm{OH}$ groups capture $\mathrm{Cs}^{+}$in both complexes. The binding between $\mathrm{Cs}^{+}$and the neutral $\mathrm{OH}$ group is probably the key to clarifying the $\mathrm{Cs}^{+}$-adsorption mechanism.

In general, point of zero charge (PZC) has been regarded as an important criterion for evaluating adsorption performance of adsorptive in aqueous solution when adsorbate has an electric charge. Hence, we have measured the PZC of the charcoal studied in the previous works and reported that the $\mathrm{Cs}^{+}$-adsorption ability of charcoal is considerably reduced when the $\mathrm{pH}$ of the aqueous solution approaches the PZC [510]. However, the ability did not completely disappear even when the $\mathrm{pH}$ of the aqueous solution decreased to slightly below the PZC; that is, the charcoal surface was charged to be slightly positive [8]. If the $\mathrm{Cs}^{+}$-adsorption ability depends only upon electrostatic attraction, the adsorption ability should be negligible when the $\mathrm{pH}$ falls below the PZC. Consequently, further investigation into the surface complexes is necessary for whole clarification of the $\mathrm{Cs}^{+}$-adsorption mechanisms.

More detailed studies using appropriate instrumental analyses are needed to further examine the $\mathrm{Cs}^{+} \mathrm{com}-$ plexes, especially those shown in Fig. 8c, e. Furthermore, we are advancing preparations for determining the surface $\mathrm{OH}$ group concentration and pore structure in order to more deeply discuss the $\mathrm{Cs}^{+}$-adsorption mechanisms.

\section{Conclusion}

The adsorption isotherms presented here demonstrated that the $\mathrm{Cs}^{+}$-adsorption ability of OC strongly depends on $\mathrm{CT}$ and reaches a maximum within a temperature range from $300{ }^{\circ} \mathrm{C}$ to $700{ }^{\circ} \mathrm{C}$. A noteworthy outcome of the present work is the IR-PA spectra of OC and CC samples. They confirmed that a considerable amount of residual $\mathrm{OH}$ groups exist on the surfaces of $\mathrm{OC}$ and $\mathrm{CC}$ synthesized at $300{ }^{\circ} \mathrm{C}$ and $500{ }^{\circ} \mathrm{C}$.

The surface $\mathrm{OH}$ groups are therefore essential to the attraction to $\mathrm{Cs}^{+}$in woody charcoal. Controlling of $\mathrm{OH}$ group decomposition and extension of specific surface area during carbonization process are essential to synthesizing woody charcoal with high performance in $\mathrm{Cs}^{+}$ adsorption.

\section{Abbreviations}

OC: Japanese oak charcoal (for instance, OC carbonized at $500^{\circ} \mathrm{C}$ for $2.0 \mathrm{~h}$ is referred to as OC500-2); CC: cellulose charcoal (for instance, CC carbonized at $700{ }^{\circ} \mathrm{C}$ for $1.0 \mathrm{~h}$ is referred to as CC700-1); IR-PA: infrared-photoacoustic; CT: carbonization temperature; $\mathrm{HT}$ : holding time; ICP-MS: inductively coupled plasma mass spectrometry; MR: mass reduction; PZC: point of zero charge.

\section{Acknowledgements}

Not applicable.

\section{Authors' contributions}

TY and SY designed this study and wrote the initial draft of the manuscript. TY prepared the charcoals used in this study and performed the experiments for $\mathrm{Cs}^{+}$adsorption. SY and YK contributed to measurements and interpretation of Raman and IR-PA spectra. KN improved a carbonization apparatus and devised an appropriate method of preparing charcoal. All authors have contributed to data collection and interpretation and critically reviewed the manuscript. All authors read and approved the final manuscript.

\section{Funding}

The authors raised no research funds from external sources for this study.

Availability of data and materials

Not applicable

\section{Competing interests}

The authors declare that they have no competing interests.

\section{Author details}

${ }_{1}^{1}$ Department of Materials and Life Science, Seikei University, 3-3-1 Kichijoji-Kitamachi, Musashino 180-8633, Japan. ${ }^{2}$ Department of Chemical Science and Technology, Faculty of Bioscience and Applied Chemistry, Hosei University, 3-7-2 Kajino, Koganei 184-8584, Japan. ${ }^{3}$ Institute of Wood Technology, Akita Prefectural University, 11-1 Kaieisaka, Noshiro 016-0876, Japan.

Received: 2 January 2019 Accepted: 14 June 2019

Published online: 21 June 2019

\section{References}

1. Narita E, Sasaki A, Aisawa S, Hirahara H (2013) Development of charcoals from corn wastes for prevention of environmental pollution. Wood Carbonization Res 9:59-67 (in Japanese) 
2. Caccin M, Giacobbo F, Da Ros M, Mariani M, Besozzi L (2013) Adsorption of uranium, cesium and strontium onto coconut shell activated carbon. J Radioanal Nucl Chem 297:9-18

3. Khandaker S, Kuba T, Kamida S, Uchikawa Y (2017) Adsorption of cesium from aqueous solution by raw and concentrated nitric acid-modified bamboo. J Environ Chem Eng 5:1456-1464

4. Khandaker S, Toyohara Y, Kuba T (2018) Adsorptive removal of cesium from aqueous solution using oxidized bamboo charcoal. Water Res Ind 19:35-46

5. Yamauchi S, Kurimoto Y, Yatagai M (2013) Cesium ion adsorption on oak charcoal in aqueous solutions. Wood Carbonization Res 10:35-6742 (in Japanese)

6. Yamauchi S, Yamagishi T, Kirikoshi K, Yatagai M (2014) Cesium adsorption from aqueous solutions onto Japanese oak charcoal I: effects of the presence of group 1 and 2 metal ions. J Wood Sci 60:473-479

7. Yamauchi S, Yamagishi T, Kirikoshi K, Yatagai M (2015) Cesium adsorption from aqueous solutions onto Japanese oak charcoal II: effects of metal ions eluted from the charcoal. J Wood Sci 61:185-191

8. Yamauchi S, Yamagishi T, Kirikoshi K, Yatagai M (2016) Cesium adsorption from aqueous solutions onto Japanese oak charcoal III: effects of waterextraction treatment. J Wood Sci 62:562-566

9. Yamagishi T, Kurimoto Y, Yamauchi S (2017) A method for visualizing cesium adsorbed on wood charcoal using SEM-EDX. Wood Sci Technol 51:413-429

10. Yamauchi S, Yamagishi T, Kirikoshi K, Yatagai M (2017) Factors governing cesium adsorption of charcoals in aqueous solution. J Wood Sci 63:183-191

11. Honma S, Sano Y, Kubota M, Uehara K, Komazawa K (2000) Chemical structure and ammonia adsorption ability of todomatsu (Abies sachalinensis) wood carbonized in nitrogen and air atmospheres. Mokuzai Gakkaishi 46:348-354 (in Japanese)

12. Ishimaru K, Hata T, Bronsveld P, Meier D, Imamura Y (2007) Spectroscopic analysis of carbonization behavior of wood cellulose and lignin. J Mater Sci 42:122-129

13. Yamauchi S (2003) Infrared photoacoustic spectra of Japanese cedar (Cryptomeria japonica D. Don) wood and bark heat-treated at temperature ranging from $200^{\circ} \mathrm{C}$ to $1100^{\circ} \mathrm{C}$. Eurasian J For Res $6: 75-78$

14. Yamauchi S, Kurimoto Y, Sakai Y (2017) Mössbauer characterization of iron in ancient buried trees excavated from the foothills of Mt, Chokai. J Nucl Radiochem Sci 17:23-298

15. Yamauchi S, Kikuchi Y, Kurimoto Y (2000) Raman spectral changes of sugi bark during thermal degradation and carbonization. Mater Sci Int 6:227-228

16. Yamauchi S, Kurimoto Y (2003) Raman spectroscopic study on pyrolyzed wood and bark of Japanese cedar: temperature dependence of Raman parameters. J Wood Sci 49:235-240

17. Fujii T, Mochidzuki K, Kobayashi S, Sakoda A (2011) Quick and simple analysis of lignocellulose ingredients by thermogravimetric analysis. J Jpn Soc Mater Cyc Was Mgt 22:293-297 (in Japanese)

18. Kawamoto H (2015) Reactions and molecular mechanisms of cellulose pyrolysis. Mokuzai Gakkaishi 61:1-24 (in Japanese)
19. Yoo KR, Ahn SJ, Kim K (1993) In-situ reflection FT-IR spectroscopic study of pyrolysis of lignite. Spectrosc Lett 26:1733-1744

20. Bellamy $L J$ (1975) The infra-red spectra of complex molecules. Chapman and Hall Ltd, London, pp 107-128

21. Shafizadeh F (1982) Introduction to pyrolysis of biomass. J Anal Appl Pyrolysis 3:283-305

22. Agarwal UP, Ralph SA (1997) FT-Raman investigation of milled wood lignins: softwood, hardwood, and chemically modified black spruce lignins. J Wood Chem Tech 31:324-344

23. Abe I, Iwasaki S, Iwata Y, Kominami H, Kera Y (1998) Relationship between method and adsorption property of charcoal. Tanso 185:277-284 (in Japanese)

24. Kitamura T, Matsumoto S, Katayama H (1999) The effect of carbonizing conditions on the properties of charcoal absorbent from cryptomeria. Mokuzai Gakkaishi 45:171-177 (in Japanese)

25. Pulido-Novicio L, Hata T, Kurimoto Y, Doi S, Ishihara S, Imamura Y (2001) Adsorption capacities and related characteristic of wood charcoal carbonized using a one-step or two-step process. J Wood Sci 47:48-57

26. Girifalco LA, Lad RA (1956) Energy of cohesion, compressibility, and the potential energy functions of the graphite system. J Chem Phys 25:693-696

27. Ohtaki H, Radnai T (1993) Structure and dynamics of hydrated ions. Chem Rev 93:1157-1204

28. Persson I (2010) Hydrated metal ions in aqueous solution: how regular are their structures? Pure Appl Chem 82:1901-1917

29. Ma JC, Dougherty DA (1997) The cation- $\pi$ interaction. Chem Rev 97:1303-1324

30. Mecozzi S, Jr West A P, Dougherty DA (1996) Cation- $\pi$ interactions in sample aromatics: electrostatics provide a predictive tool. J Am Chem Soc 118:2307-2308

31. Amicangelo JC, Armentrout PB (2000) Absolute binding energies of alkali-metal cation complexes with benzene determined by threshold collision-induced dissociation experiments and ab initio theory. J Phys Chem A 104:11420-11432

32. Sposito G (1989) The chemistry of soils. Oxford University Press, London, pp 127-147

33. Motschi H (1986) Aspects of the molecular structure in surface complexes; spectroscopic investigations. In: Stumm W (ed) Aqueous surface chemistry. John Wiley \& Sons, New York, pp 11-125

34. Mukai H, Tamura K, Kikuchi R, Takahashi Y, Yaita T, Kogure T (2018) Cesium desorption behavior of weathered biotite in Fukushima considering the actual radioactive contamination of soils. J Environ Radioact 190-191:81-89

\section{Publisher's Note}

Springer Nature remains neutral with regard to jurisdictional claims in published maps and institutional affiliations.

\section{Submit your manuscript to a SpringerOpen ${ }^{\circ}$ journal and benefit from:}

- Convenient online submission

- Rigorous peer review

- Open access: articles freely available online

- High visibility within the field

Retaining the copyright to your article

Submit your next manuscript at springeropen.com 